\title{
Measuring Patient Quality of Life Following Treatment for Alopecia
}

\author{
Kunlawat Thadanipon (iD) 1,2 \\ Poonkiat Suchonwanit (D) \\ 'Division of Dermatology, Department of \\ Medicine, Faculty of Medicine, Ramathibodi \\ Hospital, Mahidol University, Bangkok, \\ Thailand; ${ }^{2}$ Department of Clinical \\ Epidemiology and Biostatistics, Faculty of \\ Medicine, Ramathibodi Hospital, Mahidol \\ University, Bangkok, Thailand
}

\begin{abstract}
Alopecia is a challenging problem for both physicians and patients in terms of diagnosis and treatment. Alopecia usually has negative effects on patients' emotional and psychological well-being. Several studies have examined the effect of alopecia on patients' health-related quality of life (HRQoL) and have consistently reported poor scores. However, deeper insight into the impact of alopecia on affected individuals and its measurement using HRQoL questionnaires is lacking in the literature. In this article, the methods for measuring the HRQoL of patients with alopecia were comprehensively reviewed. Their applications and limitations were also discussed.
\end{abstract}

Keywords: hair loss, health-related quality of life, questionnaire, instrument, diseasespecific, patient-reported outcome

\section{Introduction}

Human hair may have little physiological importance, but its psychological counterpart is undeniable, ${ }^{1}$ contributing significantly to a person's body image and attractiveness. ${ }^{2,3}$ Hair loss, also known as alopecia, is a challenging problem for both physicians and patients worldwide. It is one of the common presenting symptoms in dermatological practice and is often a major source of distress for affected individuals. Numerous studies have been conducted to better understand its etiologies and pathophysiology and to find effective treatment options. There are several causes of hair loss, such as genetics, hormonal disorders, autoimmune disturbance, nutritional deficiency, and stress; ${ }^{4-9}$ therefore, an organized and systematic approach is needed to accurately address patients' complaints. A thorough review of medical history, complete physical examination, laboratory investigation, and scalp biopsy are essential to establish a definitive diagnosis.

Alopecia can be categorized into two groups, ie, nonscarring and scarring. The main difference between them is that scarring alopecia is accompanied by follicular fibrosis, in contrast to nonscarring alopecia, where the follicular scar is not present. ${ }^{10}$ Common nonscarring hair loss includes androgenetic alopecia (AGA), female pattern hair loss (FPHL), telogen effluvium, anagen effluvium, and alopecia areata (AA), whereas scarring alopecia, a permanent hair loss due to destruction of the hair follicles, is less frequently found and can be further divided into primary and secondary subtypes. ${ }^{10}$ Primary scarring alopecia refers to a group of disorders that primarily affect hair follicles, such as lichen planopilaris (LPP), frontal fibrosing alopecia (FFA), chronic cutaneous lupus erythematosus, and central centrifugal cicatricial alopecia. In contrast, secondary scarring alopecia represents conditions
Correspondence: Poonkiat Suchonwanit Division of Dermatology, Department of Medicine, Faculty of Medicine, Ramathibodi Hospital, Mahidol University, 270 Rama V Road, Ratchathewi, Bangkok, Thailand $\mathrm{Tel}+66-2-201 \mathrm{II} 4 \mathrm{I}$

Fax +66-2-20I-I2II Ext 4

Email poonkiat@hotmail.com 
involving the hair follicles as a bystander from any pathological processes of the surrounding tissues, such as inflammation, trauma, or infections.

Over the last decades, many therapeutic options for alopecia, including topical, intralesional, or systemic treatments, have been administered to regrow hair and to delay and stop the hair loss process. However, some medications, such as topical minoxidil and oral finasteride for AGA or corticosteroids for AA, may provide partial and temporary results and are associated with unwanted adverse effects. ${ }^{711}$ In addition, treatments for some hair loss conditions, such as severe AA and many forms of scarring alopecia, are usually ineffective..$^{10,12,13}$ Hair restoration surgery is often the treatment in alopecic cases with unresponsiveness to medical therapy or irreversible hair loss. Evidence suggests that hair loss can cause significant impairment to patients' quality of life (QoL), ${ }^{14,15}$ which is mostly experienced by the patients themselves. Therefore, the goals of the treatment of alopecia should involve not only the physical aspect of disease but also the psychosocial burden that the patients carry to help maximize the improvement of their QoL. Being able to measure patients' QoL should complement holistic patient care and facilitate the process of developing high-quality future therapeutic options through research. This article aims to review the current methods to measure the QoL of patients with alopecia and to provide insight into the current issues concerning QoL measurement in this patient group.

\section{Health-Related Quality of Life and Its Measurement}

QoL is a concept without a universally recognized definition; a widely used definition from the World Health Organization $(\mathrm{WHO})^{16}$ is as follows:

individuals' perception of their position in life in the context of the culture and value systems in which they live and in relation to their goals, expectations, standards and concerns. It is a broad ranging concept, incorporating in a complex way individuals' physical health, psychological state, level of independence, social relationships, personal beliefs and their relationships to salient features of the environment.

The Economist Intelligence Unit regards nine factors as the determinants of quality of life, ie, material wellbeing, health, political stability and security, family life, community life, climate and geography, job security, political freedom, and gender equality. ${ }^{17}$ In essence, QoL is a multidimensional concept involving many aspects of life that is difficult to measure comprehensively. ${ }^{18}$ Thus, health-related QoL (HRQoL) can be defined as the area of QoL that encompasses only factors related to an individual's health, ${ }^{19}$ and it will be the main topic of this review.

HRQoL is considered a type of patient-reported outcome (PRO) measure, a term that denotes the outcomes evaluated directly by the patient, eg, measures of symptoms, satisfaction with treatment, and HRQoL. ${ }^{20} \mathrm{PRO}$ measures, along with observer-reported outcome measures, clinician-reported outcome measures, and performance outcome measures, are in turn the components of clinical outcome assessments (COAs). ${ }^{21}$ To assess HRQoL, a regular patient interview may be carried out to gain some qualitative information, but this would not suffice if quantification of HRQoL is required for future use in either research or patient care. Therefore, HRQoL is usually assessed quantitatively using the measures described below.

HRQoL measures are usually classified into two major groups, ie, generic and specific measures. Generic measures are designed for general use in a wide range of interventions and conditions, ${ }^{22}$ thus allowing comparisons between different diseases. They can be used to assess HRQoL in the general population as well as most health conditions, including alopecia. These generic HRQoL measures comprise two types: health profiles and health indices. Health profiles are the measures that attempt to quantify HRQoL on several dimensions by means of scores obtained from respondents through questionnaires (ie, instruments). ${ }^{23}$ Many instruments have been developed for this purpose, eg, the Medical Outcomes Study 36Item Short Form Health Survey (SF-36), ${ }^{24}$ the Sickness Impact Profile (SIP), ${ }^{25}$ the Nottingham Health Profile (NHP), ${ }^{26}$ the Quality of Life Inventory (QOLI), ${ }^{27}$ the Assessment of Quality of Life (AQoL) instrument, ${ }^{28}$ and the Centers for Disease Control and Prevention HealthRelated Quality of Life Measure (CDC HRQOL-14). ${ }^{29}$ The World Health Organization Quality of Life assessment instrument (WHOQOL-100) ${ }^{16}$ and its reduced version (WHOQOL-BREF) ${ }^{30}$ although usually considered in this category, also contain domains other than health, such as the environmental domain, and thus may also be regarded as measures for general QoL (compared to HRQoL).

The other type of generic HRQoL measure is the health index, which is also known as utility. Its value normally ranges from 0 (corresponding to the worst possible health 
or death) to 1 (corresponding to the best possible health), but negative values (corresponding to health states worse than death) are sometimes possible. Theoretically, utility is assessed by direct methods, namely, preference-based measures that include standard gamble and time tradeoff. However, it can also be measured by indirect methods that use predefined population-based weights to calculate the utility from scores obtained from HRQoL instruments such as the EuroQoL 5-Dimension (EQ-5D), ${ }^{31}$ the Health Utilities Index (HUI), ${ }^{32}$ and the SF-6D (ie, a reduced version of the SF-36 developed for this purpose). ${ }^{33}$ Utility can be used by itself, but more prominently, it is used for calculating the quality-adjusted life-years (QALY), which is the most widely recommended outcome measure for economic evaluation studies. ${ }^{34}$

Conversely, specific HRQoL measures are developed to suit either the disease/condition or the population of interest. $^{35}$ While disease-specific measures can collect some information peculiar to the disease of interest that their generic counterparts cannot, they are also more responsive, ${ }^{22,36} \mathrm{ie}$, more sensitive for detecting differences or changes in disease status. ${ }^{37}$ To measure the HRQoL of alopecia patients, dermatology-specific instruments may be used justifiably. The Dermatology Life Quality Index (DLQI), ${ }^{38}$ Skindex-29 $9^{39}$ and its reduced versions (ie, Skindex-16 $6^{40}$ and Skindex-17 $7^{41}$ ), and the Dermatology Quality of Life Scales (DQoLS) ${ }^{42}$ are examples of dermatology-specific HRQoL measures. These instruments have been extensively reviewed elsewhere. ${ }^{23,43,44}$ For patients with hair diseases, including alopecia, researchers have developed a number of hair-specific HRQoL measures. Their details are discussed in the following section.

\section{Hair-Specific Health-Related Quality of Life Instruments}

Although alopecia is considered a benign process, it has been demonstrated to have a serious impact on individuals' overall QoL. A variety of measures to assess the effects of alopecia on patients' lives have been introduced and validated in the literature. The details of some of the instruments discussed in this article are presented in Table 1.

\section{Men's Hair Growth Questionnaire}

The Men's Hair Growth Questionnaire (MHGQ) is a short instrument developed for male AGA patients. Initially, 17 questions were identified from a literature review, expert opinions, focus groups of patients, and the review of related questionnaires and then underwent a substantial reduction through tests for internal consistency, test-retest reliability, construct validity, and responsiveness. The final version contains seven individual items that do not belong to any particular domain or subscale. The MHGQ was primarily designed for clinical trials because the questions directly address the changes from baseline, with reference to the start of the study. ${ }^{45}$

\section{Kingsley Alopecia Profile}

The Kingsley Alopecia Profile (KAP) is an English instrument consisting of 15 questions on five-point Likert scales, with proposed bands of total scores for interpretation. ${ }^{46}$ However, the process of its development was described in a thesis not accessible to us at the time of writing. ${ }^{47}$

\section{Women's Androgenetic Alopecia Quality of Life Questionnaire}

The Women's Androgenetic Alopecia Quality of Life Questionnaire (WAA-QOL) was developed from items regarding aspects of female patients' life affected by AGA, which were generated from a literature review, discussion with experts, and a focus group, with patients' feedback contributing to the revision. The final English version, consisting of 16 items that form only one domain, with a one-week recall period, was able to show high reliability (ie, internal consistency and test-retest reliability) but not responsiveness in the validation study (due to the intervention's lack of efficacy in the trial). ${ }^{48}$ The formally translated Brazilian Portuguese version of the WAA-QOL has been thoroughly tested for validity and reliability. ${ }^{49}$

\section{Hairdex}

The original German version of Hairdex was a modification of Skindex-29 for use in female patients with diffuse alopecia and AGA in Germany. Patients' feedback also contributed to the revision and item reduction. The final version consists of 48 items that belong to five subscales (ie, domains) proven to determine the impact of hair loss on patients' lives, including emotions, functioning, symptoms, self-confidence, and stigmatization; the first three subscales are similar to the only three subscales of the original Skindex-29 instrument, while the last two were newly added. Hairdex can be completed within 15 minutes by most patients. ${ }^{50}$ It has been translated and used in the USA, ${ }^{51,52}$ India, ${ }^{53}$ and Turkey, ${ }^{54}$ but the processes of adaptation and validation were not detailed. 
Table I Characteristics of Some Hair-Specific Health-Related Quality of Life Instruments Discussed in This Article

\begin{tabular}{|c|c|c|c|c|c|c|c|c|c|}
\hline Instrument & $\begin{array}{l}\text { Publication } \\
\text { Year }\end{array}$ & $\begin{array}{l}\text { Country } \\
\text { of Origin }\end{array}$ & Language & $\begin{array}{l}\text { Intended } \\
\text { Patient } \\
\text { Group }\end{array}$ & $\begin{array}{l}\text { Recall } \\
\text { Period }\end{array}$ & $\begin{array}{l}\text { Number } \\
\text { of Items }\end{array}$ & $\begin{array}{l}\text { Scales } \\
\text { for } \\
\text { Items }\end{array}$ & Domains & Reliability \\
\hline MHGQ & 1998 & USA & English & $\begin{array}{l}\text { AGA in } \\
\text { men }\end{array}$ & $\begin{array}{l}\text { Since the } \\
\text { start of } \\
\text { treatment }\end{array}$ & 17 & $\begin{array}{l}\text { 4- to } \\
7 \text {-point }\end{array}$ & Single & NR \\
\hline WAA-QOL & 2000 & USA & English & $\begin{array}{l}\text { AGA in } \\
\text { women }\end{array}$ & I week & 16 & 7-point & Single & $\begin{array}{l}\text { Cronbach's } \alpha \\
0.98, \text { ICC } 0.89\end{array}$ \\
\hline Hairdex & 2001 & Germany & German & $\begin{array}{l}\text { AGA and } \\
\text { diffuse } \\
\text { alopecia }\end{array}$ & NR & 48 & 5-point & $\begin{array}{l}5 \text { (emotions, functioning, } \\
\text { symptoms, self-confidence, } \\
\text { stigmatization) }\end{array}$ & $\begin{array}{l}\text { Cronbach's } \alpha \\
0.55-0.82 \text { for } \\
\text { each domain }\end{array}$ \\
\hline WHGQ & 2009 & USA & English & $\begin{array}{l}\text { AGA/ } \\
\text { FPHL in } \\
\text { women }\end{array}$ & $\begin{array}{l}\text { Since the } \\
\text { start of } \\
\text { treatment }\end{array}$ & 4 & NR & Single & $\begin{array}{l}\text { Cronbach's } \alpha \\
0.8 I \text { I, ICC } 0.89\end{array}$ \\
\hline AAQ & 2012 & Japan & Japanese & AA & I month & 7 & 5-point & $\begin{array}{l}3 \text { (restriction of activity, } \\
\text { concealment, adaptation) }\end{array}$ & $\begin{array}{l}\text { Cronbach's } \alpha \\
0.59-0.8 \mathrm{I} \text { for } \\
\text { each domain }\end{array}$ \\
\hline $\begin{array}{l}\text { Hair-Specific } \\
\text { Skindex-29 }\end{array}$ & 2012 & Spain & Spanish & $\begin{array}{l}\mathrm{FPHL} \text { in } \\
\text { women }\end{array}$ & NR & 29 & 5-point & $\begin{array}{l}3 \text { (emotions, functioning, } \\
\text { symptoms) }\end{array}$ & $\begin{array}{l}\text { Cronbach's } \alpha \\
0.96, \text { ICC } 0.98\end{array}$ \\
\hline AASIS & 2013 & USA & English & AA & I week & 13 & $\begin{array}{l}\text { II- } \\
\text { point }\end{array}$ & $\begin{array}{l}3 \text { (interference, hair loss, } \\
\text { other symptoms) }\end{array}$ & $\begin{array}{l}\text { Cronbach's } \alpha \\
0.77-0.93 \text { for } \\
\text { each domain }\end{array}$ \\
\hline AA-QLI & 2013 & Italy & Italian & AA & I month & 21 & 4-point & $\begin{array}{l}3 \text { (subjective symptoms, } \\
\text { objective signs, relationship) }\end{array}$ & $N R$ \\
\hline A-QLI & 2016 & $\begin{array}{l}\text { South } \\
\text { Africa }\end{array}$ & English & Alopecia & NR & 19 & 4-point & $\begin{array}{l}3 \text { (subjective symptoms, } \\
\text { objective signs, relationship) }\end{array}$ & $N R$ \\
\hline
\end{tabular}

Abbreviations: AA, alopecia areata; AAQ, Alopecia Areata Quality of Life; AA-QLI, Alopecia Areata Quality of Life Index; AASIS, Alopecia Areata Symptom Impact Scale; AGA, androgenetic alopecia; A-QLI, Alopecia Quality of Life Indicators; FPHL, female pattern hair loss; ICC, intraclass correlation coefficient; MHGQ, Men's Hair Growth Questionnaire; NR, not reported; WAA-QOL, Women's Androgenetic Alopecia Quality of Life Questionnaire; WHGQ, Women's Hair Growth Questionnaire.

\section{Women's Hair Growth Questionnaire}

The Women's Hair Growth Questionnaire (WHGQ) is a specific HRQoL instrument intended for use in female patients with AGA/FPHL. During its development, the initial 20 questions were identified from a literature review, focus groups of women with AGA/FPHL, and expert opinions. The patients' feedback from cognitive interviews was used to guide item revision and reduction to the final version of 4 items that assess growth of hair, amount of noticeable new hair, visibility of the scalp, and rate of hair loss since the start of the treatment. Good internal consistency, test-retest reliability, and responsiveness to change were shown. ${ }^{55}$

\section{Alopecia Areata Quality of Life}

The Alopecia Areata Quality of Life (AAQ) scale is a concise Japanese HRQoL instrument specific to AA that can be completed in two minutes. The preliminary questions were created from qualitative interviews, and the revisions were guided by patients' comments. After being tested for internal consistency and construct validity, the final version retains seven questions that contribute to three subscales, ie, restriction of activity, concealment, and adaptation, with a recall period of one month. ${ }^{56}$

\section{Hair-Specific Skindex-29}

Skindex-29 was modified to assess the HRQoL of Korean male patients with AGA by replacing the words "skin" with "scalp" and "skin condition" with "AGA" and was renamed the Hair-Specific Skindex-29. ${ }^{57}$ Details on the processes of Korean translation, adaptation, and validation were not available. Nevertheless, Skindex-29 underwent a formal translation and cross-cultural adaptation to Spanish and was thoroughly tested for validity and 
reliability by Spanish female patients with FPHL, with satisfactory face validity, construct validity, and testretest and internal consistency. Factor analysis showed 3 domains similar to those of the original Skindex-29. ${ }^{58}$ Responsiveness to change was subsequently shown in a longitudinal study. ${ }^{59}$ The Hair-Specific Skindex-29 has also been adapted for use in India ${ }^{60}$ and Russia, ${ }^{61}$ but details on the processes of adaptation and validation were not available.

\section{Alopecia Areata Symptom Impact Scale}

The Alopecia Areata Symptom Impact Scale (AASIS) was developed for AA in English using retrospective data of responses to 125 items of several HRQoL instruments, including Skindex-16 and the DLQI, from 1649 patients who participated in the National Alopecia Areata Registry of the USA as the input. Extensive reduction of items was carried out by means of cluster analysis and clinical experts' reviews to yield the final 13 items grouped into 3 subscales, ie, interference, hair loss, and other symptoms, with good internal consistency. Cognitive debriefing of participants showed acceptable content validity. ${ }^{62,63}$

\section{Alopecia Areata Quality of Life Index}

The Alopecia Areata Quality of Life Index (AA-QLI) is a disease-specific HRQoL instrument for AA in Italian that contains 21 items contributing to three domains, ie, subjective symptoms, objective signs, and relationships, with a recall period of one month. The questions were reported as being guided by answers from AA patients about the impact of AA and its treatment on their lives, but the processes of qualitative study and tests for reliability were not detailed. Good concurrent validity was shown between the total scores of the AA-QLI and the DLQI. Calculation of an index from the scores using the weights derived from structural equation modeling was also proposed. $^{64}$

\section{Alopecia Quality of Life Indicators}

Alopecia Quality of Life Indicators (A-QLI) is an adaptation of the abovementioned AA-QLI (which is specific to AA) to be used with alopecia patients in general. However, the authors acknowledged a concern over its selection bias because the development was based on a pilot study in 50 South African women with alopecia, of which LPP/FFA was the most prevalent type. This might affect the generalizability in other populations of alopecia patients. The items were quite similar to those of the AA-QLI, but with the number of questions reduced from 21 to 19 , while the three domains of the AA-QLI were retained with good internal consistency. Weighting factors for calculating an index were also proposed. ${ }^{65}$

\section{Skindex-16 for AA}

Skindex-16 for AA is a modification of Skindex-16 for use in patients with $\mathrm{AA}^{66}$ whose development is still ongoing. ${ }^{67}$

To seek information on HRQoL measures, in addition to using regular search engines, there are also certain online information sources that focus on COAs (among them, HRQoL measures), such as PROQOLID (https:// eprovide.mapi-trust.org/about/about-proqolid), which is an online database designed for searching COAs, and the COnsensus-based Standards for the selection of health Measurement Instruments (COSMIN) Database of Systematic Reviews (https://database.cosmin.nl/), which is a database dedicated to systematic reviews of outcome measurement instruments. Although not exhaustive, these tools may be considerably helpful in finding appropriate instruments of COAs to suit one's need, such as for clinical practice or research.

\section{Applications of Health-Related Quality of Life Measures}

The most prominent application of HRQoL measures is probably their use in clinical research, which is the area for which most HRQoL measures were developed. The benefit of measuring HRQoL in clinical research is obvious, as HRQoL, along with other PRO measures, represents the patients' perceptions about the effects of the disease and its treatment. Without measuring HRQoL, researchers could fail to capture the other dimensions of those effects that are also important to the patients. HRQoL measures have been progressively developed and used over the past decades in clinical studies, ${ }^{68}$ both observational and experimental. HRQoL information from healthcare research may also help in estimating the burden of disease, interpreting outcomes of clinical studies, and determining the cost-effectiveness of treatments. ${ }^{69}$ Moreover, regulatory agencies such as the US Food and Drug Administration and the European Medicines Agency recognize PRO measures, including HRQoL, in their drug evaluation process and claim substantiation. Their guidelines regarding the expected properties of PRO measures for this purpose have been 
provided. ${ }^{20,70}$ HRQoL measures, including DLQI, have been used for labeling several drugs. ${ }^{71}$

HRQoL measurement has also been increasingly encouraged to be incorporated into routine clinical practice to aid clinicians' treatment decision making. ${ }^{72}$ As the perception of disease status by clinicians and patients may not always be congruent, ${ }^{73,74}$ an explicit HRQoL assessment should provide clinicians with valuable information to support clinical decision making. Other possible benefits, such as its potential to improve clinician-patient communication, awareness of the skin disease burden, efficiency of the consultation, and clinical service administration, ${ }^{75}$ may also be relevant.

\section{Current Usage of Health-Related Quality of Life Instruments in Clinical Trials of Alopecia}

To gain an impression of the current situation of how HRQoL is measured to assess the effects of treatments for alopecia, we conducted a literature review of parallel randomized controlled trials (RCTs) on any intervention used for treating alopecia of any type that were indexed in PubMed and Embase in the past half-decade (ie, from 2016 to May 2021). Sixty-one parallel RCTs from every continent were identified. They were conducted on alopecia patients diagnosed with AA, AGA, FPHL, telogen effluvium, chemotherapy-induced alopecia, LPP, or trichotillomania and evaluated a wide range of interventions, including oral drugs, topical drugs, cosmeceuticals, medical procedures, laser and light therapies, acupuncture, injections with neurotoxin, stem cells, platelet-rich plasma, and some combinations thereof. Only eight RCTs (13.1\%) measured HRQoL as a study outcome using a generic (ie, $\mathrm{QOLI}^{76}$ ), dermatology-specific (ie, DLQI ${ }^{77-79}$ ), or hairspecific HRQoL instrument (ie, AASIS ${ }^{80,81}$ or WAAQoL $\left.{ }^{82,83}\right)$. Among these eight studies, the patients were blinded in four. ${ }^{76,79-81}$ The patients in the other four studies were aware of the treatment given.

These findings suggest that HRQoL is rarely measured in RCTs of alopecia treatments. Blinding of study participants is also surprisingly underused.

\section{Some Issues Concerning the Use of Health-Related Quality of Life Measures in Alopecia Patients}

As demonstrated above, HRQoL measurement is an area that is still underappreciated in clinical trials on alopecia patients, despite the considerable number of hair-specific HRQoL instruments available. This problem could be addressed by the advent of a core outcome set, ie, a minimum set of outcome measures that have been agreed upon to be important and necessarily reported in all clinical trials for a specific condition, ${ }^{84}$ which should standardize the types of outcome measures used and promote comparability of results across trials evaluating the same disease. ${ }^{85-88}$ Core outcome sets have been developed for several skin diseases, ${ }^{89}$ but one for hair loss/nonscarring alopecia is still under development. ${ }^{90}$ However, the Alopecia Areata Consensus of Experts (ACE) group has proposed a consensus on the outcome measures for AA patients, which recommended that measurement of HRQoL is required in clinical trials. ${ }^{91}$ If core outcome sets for alopecia have been successfully developed and complied with, the problem might be resolved to some extent. Nevertheless, for clinical trials using split-scalp, intraindividual comparisons, it should be difficult to apply HRQoL measurements because each patient, whose HRQoL is measured once, receives more than one treatment.

Moreover, bias in HRQoL measurement does not seem to be rigorously avoided. HRQoL is assessed by the patients themselves. Therefore, failure to blind the patients results in an increased risk of measurement bias. The sequence of measurement of multiple outcomes on the same visit can also be important. It is recommended that PRO assessments should be completed before the outcomes by other parties, such as clinician-reported outcomes or objective measures, are assessed. Otherwise, the patient's responses to PRO measures may be influenced by their knowledge of those outcomes. ${ }^{70}$ Methodological weaknesses in the conduct of clinical trials can undermine the validity of the study, of which the results may consequently deviate from the truth.

Another issue of concern for HRQoL instruments is that they are developed and validated for a specific group of people or patients. Validity might not be retained if the instrument was modified or used with people different from the intended population or even when the mode of administration was changed, eg, from paper to electronic format or from an interview to self-administration. In these situations, the instrument should be validated again to ensure its ability to measure what it is designed for. ${ }^{70}$

In addition, although measurement of HRQoL in clinical practice should also be encouraged because of the potential benefits, the burden of using HRQoL to both 
clinicians and patients may be a barrier against its use. ${ }^{75}$ Therefore, shorter instruments, which impose less burden, with acceptable psychometric properties might gain advantages in this regard.

\section{Conclusions}

There are several dermatology- and hair-specific HRQoL instruments available, some of which are well developed and possess good measurement properties. However, underuse of these instruments in both clinical trials and clinical practice and a lack of standardization and regulation of their use are current issues. Core outcome sets should be developed for clinical trials on alopecia, and measuring HRQoL in clinical practice should be encouraged.

\section{Disclosure}

The authors report no conflicts of interest in this work.

\section{References}

1. Papa CM. Hair. In: Walker HK, Hall WD, Hurst JW, editors. Clinical Methods: The History, Physical, and Laboratory Examinations. Boston: Butterworths; 1990:532-535.

2. Rusticus S. Body image. In: Michalos AC, editor. Encyclopedia of Quality of Life and Well-Being Research. Dordrecht: Springer Netherlands; 2014:420-423.

3. Kwan S. Beauty. In: Michalos AC, editor. Encyclopedia of Quality of Life and Well-Being Research. Dordrecht: Springer Netherlands; 2014:335-337.

4. Chanprapaph K, Sutharaphan T, Suchonwanit P. Scalp biophysical characteristics in males with androgenetic alopecia: a comparative study with healthy controls. Clin Interv Aging. 2021;16:781-787. doi:10.2147/CIA.S310178

5. Rojhirunsakool S, Suchonwanit P. Parietal scalp is another affected area in female pattern hair loss: an analysis of hair density and hair diameter. Clin Cosmet Investig Dermatol. 2017;11:7-12. doi:10.2147/CCID.S153768

6. Meephansan J, Thummakriengkrai J, Ponnikorn S, Yingmema W, Deenonpoe R, Suchonwanit P. Efficacy of topical tofacitinib in promoting hair growth in non-scarring alopecia: possible mechanism via VEGF induction. Arch Dermatol Res. 2017;309(9):729-738. doi:10.1007/s00403-017-1777-5

7. Suchonwanit P, Iamsumang W, Rojhirunsakool S. Efficacy of topical combination of $0.25 \%$ finasteride and $3 \%$ minoxidil versus $3 \%$ minoxidil solution in female pattern hair loss: a randomized, double-blind, controlled study. Am J Clin Dermatol. 2019;20 (1):147-153. doi:10.1007/s40257-018-0387-0

8. Chanasumon N, Sriphojanart T, Suchonwanit P. Therapeutic potential of bimatoprost for the treatment of eyebrow hypotrichosis. Drug Des Devel Ther. 2018;12:365-372. doi:10.2147/DDDT.S156467

9. Chanprapaph K, Udompanich S, Visessiri Y, Ngamjanyaporn P, Suchonwanit P. Nonscarring alopecia in systemic lupus erythematosus: a cross-sectional study with trichoscopic, histopathologic, and immunopathologic analyses. $J$ Am Acad Dermatol. 2019;81 (6):1319-1329. doi:10.1016/j.jaad.2019.05.053

10. Harnchoowong S, Suchonwanit P. PPAR- $\gamma$ agonists and their role in primary cicatricial alopecia. PPAR Res. 2017;2017:2501248. doi: $10.1155 / 2017 / 2501248$
11. Sriphojanart T, Khunkhet S, Suchonwanit P. A retrospective comparative study of the efficacy and safety of two regimens of diphenylcyclopropenone in the treatment of recalcitrant alopecia areata. Dermatol Reports. 2017;9(2):7399. doi:10.4081/dr.2017.7399

12. Suchonwanit P, Hector CE, Bin Saif GA, McMichael AJ. Factors affecting the severity of central centrifugal cicatricial alopecia. Int J Dermatol. 2016;55(6):e338-343. doi:10.1111/ijd.13061

13. Suchonwanit $P$, Chalermroj N, Khunkhet $S$. Low-level laser therapy for the treatment of androgenetic alopecia in Thai men and women: a 24-week, randomized, double-blind, sham device-controlled trial. Lasers Med Sci. 2019;34(6):1107-1114. doi:10.1007/s10103-018-02699-9

14. Alirezaei P, Ahmadpanah M, Rezanejad A, Soltanian A, Sadeghi Bahmani D, Brand S. Compared to controls, individuals with lichen planopilaris have more depression, a lower self-esteem, and a lower quality of life. Neuropsychobiology. 2019;78(2):95-103. doi:10.1159/ 000499135

15. Titeca G, Goudetsidis L, Francq B, et al. 'The psychosocial burden of alopecia areata and androgenetica': a cross-sectional multicentre study among dermatological out-patients in 13 European countries. J Eur Acad Dermatol Venereol. 2020;34(2):406-411. doi:10.1111/jdv.15927

16. Whoqol Group. The World Health Organization quality of life assessment (WHOQOL): position paper from the World Health Organization. Soc Sci Med. 1995;41(10):1403-1409. doi:10.1016/ 0277-9536(95)00112-K

17. The economist intelligence unit's quality-of-life index. 2005. Available from: https://www.economist.com/media/pdf/quality_of life.pdf. Accessed May 24, 2021.

18. Veenhoven R. Quality of life (QOL), an overview. In: Michalos AC, editor. Encyclopedia of Quality of Life and Well-Being Research. Dordrecht: Springer Netherlands; 2014:5265-5269.

19. Torrance GW. Utility approach to measuring health-related quality of life. J Chronic Dis. 1987;40(6):593-603. doi:10.1016/0021-9681(87) 90019-1

20. Committee for medicinal products for human use. Reflection paper on the regulatory guidance for the use of health-related quality of life (HRQL) measures in the evaluation of medicinal products. London: European Medicines Agency; 2005.

21. U.S. Food \& Drug Administration. Clinical outcome assessment (COA): frequently asked questions. Available from: https://www. fda.gov/about-fda/clinical-outcome-assessment-coa-frequently-asked -questions. Accessed May 24, 2021.

22. Wiebe S, Guyatt G, Weaver B, Matijevic S, Sidwell C. Comparative responsiveness of generic and specific quality-of-life instruments. $J$ Clin Epidemiol. 2003;56(1):52-60. doi:10.1016/S0895-4356(02) 00537-1

23. Kini SP, DeLong LK. Overview of health status quality-of-life measures. Dermatol Clin. 2012;30(2):209-221, xiii. doi:10.1016/j. det.2011.11.007

24. Brazier JE, Harper R, Jones NM, et al. Validating the SF-36 health survey questionnaire: new outcome measure for primary care. $B M J$. 1992;305(6846):160-164. doi:10.1136/bmj.305.6846.160

25. Gilson BS, Gilson JS, Bergner M, et al. The sickness impact profile. Development of an outcome measure of health care. Am J Public Health. 1975;65(12):1304-1310. doi:10.2105/AJPH.65.12.1304

26. Hunt SM, McKenna SP, McEwen J, Williams J, Papp E. The Nottingham health profile: subjective health status and medical consultations. Soc Sci Med A. 1981;15(3 Pt 1):221-229. doi:10.1016/0271-7123(81)90005-5

27. Frisch MB, Cornell J, Villanueva M, Retzlaff PJ. Clinical validation of the quality of life inventory: a measure of life satisfaction for use in treatment planning and outcome assessment. Psychol Assess. 1992;4:92-101. doi:10.1037/1040-3590.4.1.92

28. Hawthorne G, Richardson J, Osborne R. The assessment of quality of life (AQoL) instrument: a psychometric measure of health-related quality of life. Qual Life Res. 1999;8(3):209-224. doi:10.1023/ A:1008815005736 
29. Moriarty DG, Zack MM, Kobau R. The centers for disease control and prevention's healthy days measures - population tracking of perceived physical and mental health over time. Health Qual Life Outcomes. 2003;1(1):37. doi:10.1186/1477-7525-1-37

30. The WHOQOL Group. Development of the World Health Organization WHOQOL-BREF quality of life assessment. Psychol Med. 1998;28(3):551-558. doi:10.1017/S0033291798006667

31. Janssen MF, Pickard AS, Golicki D, et al. Measurement properties of the EQ-5D-5L compared to the EQ-5D-3L across eight patient groups: a multi-country study. Qual Life Res. 2013;22 (7):1717-1727. doi:10.1007/s11136-012-0322-4

32. Horsman J, Furlong W, Feeny D, Torrance G. The Health Utilities Index (HUI): concepts, measurement properties and applications. Health Qual Life Outcomes. 2003;1:54. doi:10.1186/1477-7525-1-54

33. Brazier J, Roberts J, Deverill M. The estimation of a preference-based measure of health from the SF-36. J Health Econ. 2002;21(2):271-292. doi:10.1016/S0167-6296(01)00130-8

34. Thavorncharoensap M. Measurement of utility. J Med Assoc Thai. 2014;97(Suppl 5):S43-49.

35. Cesnales NI, Thyer BA. Health-related quality of life measures. In: Michalos AC, editor. Encyclopedia of Quality of Life and Well-Being Research. Dordrecht: Springer Netherlands; 2014:2809-2814.

36. Janković S, Perić J, Maksimović N, et al. Quality of life in patients with alopecia areata: a hospital-based cross-sectional study. $J$ Eur Acad Dermatol Venereol. 2016;30(5):840-846. doi:10.1111/ jdv. 13520

37. Apolone G, De Carli G, Brunetti M, Garattini S. Health-related quality of life (HR-QOL) and regulatory issues. An assessment of the European Agency for the Evaluation of Medicinal Products (EMEA) recommendations on the use of HR-QOL measures in drug approval. Pharmacoeconomics. 2001;19(2):187-195. doi:10.2165/00019053-200119020-00005

38. Finlay AY, Khan GK. Dermatology Life Quality Index (DLQI)--a simple practical measure for routine clinical use. Clin Exp Dermatol. 1994;19(3):210-216. doi:10.1111/j.1365-2230.1994.tb01167.x

39. Chren MM, Lasek RJ, Quinn LM, Mostow EN, Zyzanski SJ. Skindex, a quality-of-life measure for patients with skin disease: reliability, validity, and responsiveness. $J$ Invest Dermatol. 1996;107(5):707-713. doi:10.1111/1523-1747.ep12365600

40. Chren MM, Lasek RJ, Sahay AP, Sands LP. Measurement properties of Skindex-16: a brief quality-of-life measure for patients with skin diseases. J Cutan Med Surg. 2001;5(2):105-110. doi:10.1177/ 120347540100500202

41. Nijsten TE, Sampogna F, Chren MM, Abeni DD. Testing and reducing skindex-29 using Rasch analysis: skindex-17. J Invest Dermatol. 2006;126(6):1244-1250. doi:10.1038/sj.jid.5700212

42. Morgan M, McCreedy R, Simpson J, Hay RJ. Dermatology quality of life scales--a measure of the impact of skin diseases. Br J Dermatol. 1997;136(2):202-206.

43. Both H, Essink-Bot ML, Busschbach J, Nijsten T. Critical review of generic and dermatology-specific health-related quality of life instruments. $J$ Invest Dermatol. 2007;127(12):2726-2739. doi:10.1038/sj.jid.5701142

44. Lewis VJ, Finlay AY. A critical review of quality-of-life scales for psoriasis. Dermatol Clin. 2005;23(4):707-716. doi:10.1016/j. det.2005.05.016

45. Barber B, Kaufman K, Kozloff R, Girman C, Guess H. A hair growth questionnaire for use in the evaluation of therapeutic effects in men. $J$ Dermatol Treat. 1998;9(3):181-186. doi:10.3109/0954663 9809160551

46. The Kingsley Alopecia Profile (KAP). Available from: https://world trichologysociety.org/society/knowledgebase/the-kingsley-alopeciaprofile-kap/. Accessed May 24, 2021.

47. Kingsley D. The Development and Validation of a Quality of Life Measure for the Impact of Androgen-Dependent Alopecia. Portsmouth: Portsmouth University; 1999.
48. Dolte KS, Girman CJ, Hartmaier S, Roberts J, Bergfeld W, Waldstreicher J. Development of a health-related quality of life questionnaire for women with androgenetic alopecia. Clin Exp Dermatol. 2000;25(8):637-642. doi:10.1046/j.13652230.2000.00726.x

49. Shimizu GKM, Wedy GF, Schaefer LV, Ramos PM, Miot HA. Translation into Portuguese language (Brazil), transcultural adaptation and validation of the quality of life questionnaire in female pattern hair loss (WAA-QoL-BP). An Bras Dermatol. 2018;93 (5):701-706. doi:10.1590/abd1806-4841.20187452

50. Fischer TW, Schmidt S, Strauss B, Elsner P. [Hairdex: a tool for evaluation of disease-specific quality of life in patients with hair diseases]. Hautarzt. 2001;52(3):219-227. German. doi:10.1007/ s001050051293

51. Freites-Martinez A, Shapiro J, Chan D, et al. Endocrine therapy-induced alopecia in patients with breast cancer. JAMA Dermatol. 2018;154(6):670-675. doi:10.1001/jamadermatol.20 18.0454

52. Freites-Martinez A, Chan D, Sibaud V, et al. Assessment of quality of life and treatment outcomes of patients with persistent postchemotherapy alopecia. JAMA Dermatol. 2019;155(6):724-728. doi:10.1001/jamadermatol.2018.5071

53. Sawant N, Chikhalkar S, Mehta V, Ravi M, Madke B, Khopkar U. Androgenetic Alopecia: quality-of-life and associated lifestyle patterns. Int $J$ Trichology. 2010;2(2):81-85. doi:10.4103/09747753.77510

54. Gonul M, Cemil BC, Ayvaz HH, Cankurtaran E, Ergin C, Gurel MS. Comparison of quality of life in patients with androgenetic alopecia and alopecia areata. An Bras Dermatol. 2018;93(5):651-658. doi:10.1590/abd1806-4841.20186131

55. Harness J, Mamolo C, Olsen E, Price V. The women's hair growth questionnaire: development and validation of a patient-reported measure for treatment efficacy in androgenetic alopecia. $\mathrm{J} \mathrm{Am} \mathrm{Acad}$ Dermatol. 2009;60(3):AB100.

56. Endo Y, Miyachi Y, Arakawa A. Development of a disease-specific instrument to measure quality of life in patients with alopecia areata. Eur J Dermatol. 2012;22(4):531-536. doi:10.1684/ejd.2012.1752

57. Han SH, Byun JW, Lee WS, et al. Quality of life assessment in male patients with androgenetic alopecia: result of a prospective, multicenter study. Ann Dermatol. 2012;24(3):311-318. doi:10.5021/ ad.2012.24.3.311

58. Guerra-Tapia A, Buendía-Eisman A, Ferrando J. Validation of a cross-cultural adaptation of the hair specific Skindex-29 scale to Spanish. Actas Dermosifiliogr. 2018;109(5):424-431. doi:10.1016/j. ad.2018.02.007

59. Guerra-Tapia A, Buendía-Eisman A, Ferrando Barbera J. Final phase in the validation of the cross-cultural adaptation of the hair-specific Skindex-29 questionnaire into Spanish: sensitivity to change and correlation with the 12-item short-form health survey. Actas Dermosifiliogr. 2019;110(10):819-829. doi:10.1016/j.ad.2019.06.003

60. Gupta S, Goyal I, Mahendra A. Quality of life assessment in patients with androgenetic alopecia. Int $J$ Trichology. 2019;11(4):147-152. doi:10.4103/ijt.ijt_6_19

61. Romanova Y, Romanov DV, Brazhnikov A, Voronova EI, Lvov AN, Potekaev NN. Perspective targets for secondary prevention of quality of life decrease and psychosomatic disorders in alopecia: results of an observational study. Profilakticheskaya Meditsina. 2019;22 (5):104-111. doi:10.17116/profmed201922051104

62. Mendoza TR, Osei JS, Shi Q, Duvic M. Development of the alopecia areata symptom impact scale. J Investig Dermatol Symp Proc. 2013;16(1):S51-52. doi:10.1038/jidsymp.2013.19

63. Mendoza TR, Osei J, Duvic M. The utility and validity of the alopecia areata symptom impact scale in measuring disease-related symptoms and their effect on functioning. J Investig Dermatol Symp Proc. 2018;19(1):S41-s46. doi:10.1016/j.jisp.2017.10.009 
64. Fabbrocini G, Panariello L, De Vita V, et al. Quality of life in alopecia areata: a disease-specific questionnaire. $J$ Eur Acad Dermatol Venereol. 2013;27(3):e276-281. doi:10.1111/j.14683083.2012.04629.x

65. Dlova NC, Fabbrocini G, Lauro C, Spano M, Tosti A, Hift RH. Quality of life in South African Black women with alopecia: a pilot study. Int J Dermatol. 2016;55(8):875-881. doi:10.1111/ijd.13042

66. SKINDEX-16 for Alopecia Areata (SKINDEX-16 for AA). Available from: https://eprovide.mapi-trust.org/instruments/skindex-16-foralopecia-areata. Accessed May 24, 2021.

67. Aldhouse NVJ, Kitchen H, Knight S, et al. "'You lose your hair, what's the big deal?' I was so embarrassed, I was so self-conscious, I was so depressed:" a qualitative interview study to understand the psychosocial burden of alopecia areata. J Patient Rep Outcomes. 2020;4(1):76. doi:10.1186/s41687-020-00240-7

68. Finlay AY. Quality of life in dermatology: after 125 years, time for more rigorous reporting. $B r \quad J$ Dermatol. 2014;170(1):4-6. doi:10.1111/bjd.12737

69. McCombs K, Chen SC. Patient preference quality of life measures in dermatology. Dermatol Ther. 2007;20(2):102-109. doi:10.1111/ j.1529-8019.2007.00118.x

70. Food and Drug Administration. Guidance for industry patient-reported outcome measures: use in medical product development to support labeling claims. U.S. Department of Health and Human Services; 2009.

71. Arnould B, Pierson RF, Chan E, Savre I, Acquadro C. A review of clinical outcome assessment labeling in Europe and in the United States (2013-2016). Value Health. 2017;20(9):A742. doi:10.1016/j. jval.2017.08.2051

72. Salek S, Roberts A, Finlay AY. The practical reality of using a patient-reported outcome measure in a routine dermatology clinic. Dermatology. 2007;215(4):315-319. doi:10.1159/000107625

73. Reid EE, Haley AC, Borovicka JH, West DP, Wickless H. Quality of life correlates more closely with patient-rated versus physician-rated hair loss severity in women with non-scarring alopecia. $J$ Investigat Dermatol. 2010;130:S45.

74. Reid EE, Haley AC, Borovicka JH, et al. Clinical severity does not reliably predict quality of life in women with alopecia areata, telogen effluvium, or androgenic alopecia. J Am Acad Dermatol. 2012;66(3): e97-102. doi:10.1016/j.jaad.2010.11.042

75. Finlay AY, Salek MS, Abeni D, et al. Why quality of life measurement is important in dermatology clinical practice: an expert-based opinion statement by the EADV task force on quality of life. $J$ Eur Acad Dermatol Venereol. 2017;31(3):424-431. doi:10.1111/ jdv. 13985

76. Leppink EW, Redden SA, Grant JE. A double-blind, placebo-controlled study of inositol in trichotillomania. Int Clin Psychopharmacol. 2017;32(2):107-114. doi:10.1097/YIC.0000 000000000156

77. Chen Q, Tao Y, Wang L, Zhang J, Sun B, Yang X. A randomized controlled clinical study of acupuncture therapy for Seborrheic alopecia in young and middle ages: study protocol clinical trial (SPIRIT compliant). Medicine. 2020;99(17):e19842. doi:10.1097/ MD.0000000000019842

78. Katoulis AC, Liakou AI, Koumaki D, et al. A randomized, single-blinded, vehicle-controlled study of a topical active blend in the treatment of androgenetic alopecia. Dermatol Ther. 2020;33(4): e13734. doi:10.1111/dth.13734
79. Tsai TF, Choi GS, Kim BJ, et al. Prospective randomized study of sexual function in men taking dutasteride for the treatment of androgenetic alopecia. J Dermatol. 2018;45(7):799-804. doi:10.1111/ 1346-8138.14329

80. Lai VWY, Chen G, Gin D, Sinclair R. Cyclosporine for moderate-tosevere alopecia areata: a double-blind, randomized, placebo-controlled clinical trial of efficacy and safety. $J$ Am Acad Dermatol. 2019;81(3):694-701. doi:10.1016/j.jaad.2019.04.053

81. Lai VWY, Chen G, Sinclair R. Impact of cyclosporin treatment on health-related quality of life of patients with alopecia areata. $J$ Dermatolog Treat. 2021;32(2):250-257. doi:10.1080/ 09546634.2019.1654068

82. da Silveira SP, Moita SRU, da Silva SV, Rodrigues M, da Silva DFT, Pavani C. The role of photobiomodulation when associated with microneedling in female pattern hair loss: a randomized, double blind, parallel group, three arm, clinical study protocol. Medicine. 2019;98(12):e14938. doi:10.1097/MD.0000000000014938

83. Ramos PM, Sinclair RD, Kasprzak M, Miot HA. Minoxidil $1 \mathrm{mg}$ oral versus minoxidil $5 \%$ topical solution for the treatment of female-pattern hair loss: a randomized clinical trial. $\mathrm{J} \mathrm{Am} \mathrm{Acad}$ Dermatol. 2020;82(1):252-253. doi:10.1016/j.jaad.2019.08.060

84. Williamson PR, Altman DG, Blazeby JM, et al. Developing core outcome sets for clinical trials: issues to consider. Trials. 2012;13:132. doi:10.1186/1745-6215-13-132

85. Kanokrungsee S, Anuntrangsee T, Tankunakorn J, Srisuwanwattana P, Suchonwanit P, Chanprapaph K. Rituximab therapy for treatment of pemphigus in Southeast Asians. Drug Des Devel Ther. 2021;15:1677-1690. doi:10.2147/DDDT.S306046

86. Rattanakaemakorn P, Pinyowiwat P, Iamsumang W, Chanprapaph K, Suchonwanit P. Incidence and risk factors of hepatic fibrosis in psoriatic patients receiving methotrexate with concomitant acitretin therapy and methotrexate monotherapy. Drug Des Devel Ther. 2021;15:2299-2307. doi:10.2147/DDDT.S304168

87. Chanprapaph K, Fakprapai W, Limtong P, Suchonwanit P. Nailfold capillaroscopy with USB digital microscopy in connective tissue diseases: a comparative study of 245 patients and healthy controls. Front Med. 2021;8:683900. doi:10.3389/fmed.2021.683900

88. Rattanakaemakorn P, Triyangkulsri K, Iamsumang W, Suchonwanit P. 308-nm excimer lamp vs. combination of 308-nm excimer lamp and $10 \%$ liquor carbonis detergens in patients with scalp psoriasis: a randomized, single-blinded, controlled trial. Front Med. 2021;8:677948. doi:10.3389/fmed.2021.677948

89. Prinsen CAC, Spuls PI, Kottner J, et al. Navigating the landscape of core outcome set development in dermatology. J Am Acad Dermatol. 2019;81(1):297-305. doi:10.1016/j.jaad.2019.03.009

90. Core outcome set for hair loss/non-scarring alopecia. Available from: https://www.cometinitiative.org/Studies/Details/759. Accessed May 24, 2021.

91. Meah N, Wall D, York K, et al. The Alopecia Areata Consensus of Experts (ACE) study part II: results of an international expert opinion on diagnosis and laboratory evaluation for alopecia areata. $J$ Am Acad Dermatol. 2021;84(6):1594-1601. doi:10.1016/j.jaad.2020.09.028 


\section{Publish your work in this journal}

Patient Preference and Adherence is an international, peer-reviewed, open access journal that focusing on the growing importance of patient preference and adherence throughout the therapeutic continuum. Patient satisfaction, acceptability, quality of life, compliance, persistence and their role in developing new therapeutic modalities and compounds to optimize clinical outcomes for existing disease

Submit your manuscript here: https://www.dovepress.com/patient-preference-and-adherence-journa states are major areas of interest for the journal. This journal has been accepted for indexing on PubMed Central. The manuscript management system is completely online and includes a very quick and fair peer-review system, which is all easy to use. Visit http:// www.dovepress.com/testimonials.php to read real quotes from published authors. 